\title{
The Role of High Technology in a Regional Economy
}

\author{
Jim Porter \\ Head of Information Industries Group, Scottish Enterprise \\ 120 Bothwell Street, Glasgow G2 7JP, Scotland, UK \\ Telephone +44(0)1412282770 \\ Fax: +44 (0) 1412282327 \\ jim.porter@scotent.co.uk
}

\begin{abstract}
This paper presents the underlying concepts and the aims of economic development utilising a cluster based approach with particular reference to the impact and role of high technology in a regional economy.
\end{abstract}

Keywords

Cluster, Technology, Knowledge.

\section{INTRODUCTION}

The subject of the Role of High Technology in a Regional Economy is very important to Scotland's economy and in particular to the Information Industries Group within Scottish Enterprise. Scottish Enterprise is immersed in the consideration of this topic and is currently involved in the delivery of key cluster strategies complemented by initiatives such as the Scottish Business Birth Rate programme, Commercialisation through collaboration between Universities and Industry and a current investigation of what creates Global Companies. 


\section{SCOTLAND'S HERITAGE OF INVENTIVENESS}

Scotland has been engaged in the process of creating Intellectual Capital for centuries and Scots have blazed a trail in many branches of science and engineering from astronomy to optoelectronics, steam power to semiconductors. That we no longer remember the symptoms of scurvy or fear the pain and infection of surgery can be attributed to the contribution of Scots doctors. We take the telephone for granted and do not think twice about tyres, both invented by Scots.

Yet, while our science and technology continues to be utilised and exploited around the world, we have failed to exploit it in our own country. This paper gives a brief overview of how Scotland is positioning itself for the next millennium, and is grasping the essential issues relating to success in a knowledge based society, that the Public sector has a significant role to play in creating in partnership with Industry and Academia the right environment and that it is small, flexible and responsive nations, committed to embracing change as a competitive weapon that will succeed.

How do we generate more higher value added activity in our economy which will offset the threat from cheap labour countries and low cost emerging economies? Scottish Enterprise has adopted a cluster-based approach to developing value networks which optimise current Scottish-based capability in key clusters, address the emerging Knowledge Economy, support the new business models which emerge and ensure that the people of Scotland have the necessary skills and access to the opportunities.

\section{PURPOSE OF SCOTTISH ENTERPRISE}

Scottish Enterprise was established in 1991 as a result of the merger of the previous economic development agency and the national training agency. Our purpose is to create jobs and prosperity for the people of Scotland, to ensure that Scotland enters the 21 st century as a wealthy, strong, productive, internationally competitive economy. We are not a government department but a unique kind of organisation which exists at arms length from government. We are funded by a Secretary of State with a block of money to pursue specific objectives with regard to economic development in Scotland, and are given a large degree of freedom in how we go about that task. Some may see this as an example of big interventionist centrally planned government. Nothing could be further from the truth Ronald Reagan commented that the nine most dangerous words in the English language were "I'm from the government and I'm here to help". Much of 
our role is not to do things but to remove the barriers which stop the market from operating effectively and enable businesses to succeed.

We believe that public sector organisations like ours have a significant role to play in creating, in partnership with industry and academia, the right environment, and that it is small, flexible and responsive nations committed to embracing change as a competitive weapon that will succeed. We are also, unlike many other agencies, a "one stop shop" which addresses all aspects of economic development.

We have the role of developing existing businesses for the knowledge economy, creating new sustainable businesses, attracting inward investment, increasing exports, providing the correct skills and knowledge for a sustainable economy, the provision of land, property and infrastructure and providing the nation with access to opportunity.

At the heart of Scottish Enterprise lies Scottish Enterprise Operations, comprising our Skills Directorate, Locate in Scotland (our Inward Investment arm), Scottish Trade International (our Export arm), Scottish Development Finance (responsible for generating strategic company investment) and the Scottish Business Directorate, which is charged with delivering strategic objectives in collaboration with our Industry and network partners.

Our strategy is informed by several economic and technology drivers. Political and economic liberalisation and deregulation has created more emergent players across the world, increased linkages through trade liberalisation and is changing the scale and complexity of world trade. Advances in computing power, convergence of information and communications technology such as the Internet and emerging opportunities in Biotechnology, nanotechnology which is blurring the boundaries of traditional sectors and products.

\section{A KNOWLEDGE BASED ECONOMY}

The combination of information, new products, shortening cycle times is leading to competitive advantage for smart regions from innovation, creativity and advanced sophisticated networks of people collaborating for the common good. The business model is changing as witnessed in a comparison of market capitalisation. The value of two of the world's leading corporations, Intel and Microsoft far outweighs that of traditional corporations such as GM, Ford, Sears Roebuck etc. A very different world is emerging, namely the knowledge-based economy. 
Scottish Enterprise has adopted a Cluster based approach to optimise Scotland's economy into the next millennium. The main drivers of economic growth, wealth creation and job opportunities - rarely exist in isolation, but often are found in local 'clusters' of mutually supportive industries. Studies consistently show that economic growth tends to be concentrated in industries or groups of related industries, in a geographical area with close links between customers, suppliers, academic institutions and competitors. There are a number of effects where there is a strong cluster, such as, for example:

- Foreign companies may be drawn to locate in areas where there is a strong cluster environment with a ready-made infrastructure, access to markets and available skills.

- New businesses spring up to service the requirements of successful local industries, and, in turn, more new businesses will spring up to service their needs.

- People with good ideas and specialised skills are drawn to these areas and their input increases the momentum of the local economy as it develops and expands.

- While an individual cluster provides greater diversity than a single industry, in a globally competitive economic climate of change and uncertainty, multiple clusters spread development risks even further. Accordingly, multiple clusters represent an opportunity for a region to develop a balanced portfolio of economic assets that is capable overall of smoothing out some of the stresses and strains of modern economic global market forces.

\section{PUBLIC SECTOR ROLE IN A CLUSTER BASED APPROACH}

While nations and regions may compete globally for mobile investment, only firms and industries compete globally in product markets. The rational development of multiple clusters within a region is a complex and challenging task demanding deep industry knowledge, and a detailed understanding of the drivers of strategic change operating in the global business environment.

In this cluster-based scenario the role of a regional economic development agency may be broadly summarised as:

- To create and communicate a distinctive and challenging economic vision in collaboration with key partners and stakeholders.

- To improve the availability, quality, and cost effectiveness of all components of the cluster such as identifying engines for growth

- To create a context that fosters innovation and upgrading; and

- To realise knowledge building opportunities for generating cross cluster synergy 


\section{CLUSTER PRIORITIES}

Scottish Enterprise's strategy to help generate jobs and prosperity for the people of Scotland incorporates a wide variety of key industries and enabling technologies. Some examples are Information Industries (including Electronics, Software \& Multimedia), Biotechnology, Education Services, Energy, Financial Services, Food. Since the introduction of Scottish Enterprise's strategy in 1994, the range of projects and programmes has been directed at building strong clusters.

\subsection{The electronics cluster}

Scotland's Electronics cluster provides an example of how has this been achieved.

- Attract inward investment: With an already strong inward investment in electronics particularly in the production of PC's of which we produce $35 \%$ of Europe's and $10 \%$ of world demand, a critical gap in Scotland's supply capability was monitors. Coupled to expertise in state of the art LCD panel research in our universities we have attracted Chunghwa and Lite-on to locate in our Silicon Glen.

- Build and anchor the local customer and supply base: Scotland also manufactures $60 \%$ of Europe's Workstations, $50 \%$ of Europe's ATMs and $70 \%$ of Europe's notebooks and because these companies operate in a global market, and, as such, demand and drive extremely high standards of their suppliers, Scottish Enterprise has worked closely with the local companies in upgrading local supply capability and penetrating international markets.

- Transportation and communications infrastructure: Many major blue chip organisations use Scotland as the Gateway to Europe and this is reflected in its transport infrastructure and highly sophisticated deregulated telecommunications environment.

- Education and training programmes: Through the strong links that Scottish Enterprise has built and fostered with industry bodies and academic institutions, projects are being developed to upgrade the skills of the existing Scottish workforce and educate future generations to the high level required by the electronics cluster. Scottish Universities have collaborated in the development of courses directly in support of the Industries needs such as Systems level integration, Integrated manufacturing programmes and research and design competencies.

- Forums to build and exchange knowledge: A substantial amount of effort has been placed on securing Industry support and participation in key programmes identified by both the Industry and Scottish Enterprise. Examples of collaborative partnerships include:

Scottish Electronics Forum (SEF) SEF comprises 40 Senior Executives from blue chip OEM's and Academia including IBM, Motorola, NEC, Compaq, Polaroid, H-P, NCR, JVC, Strathclyde, Glasgow, Heriot Watt and Edinburgh Universities. SE collaborates with SEF in the development of strategic 
programmes addressing Commercialisation, Skills, R \& D and Supply. One critical initiative identified in collaboration with Industry is our Product Dept Network programme

Scottish Product Development Network (SPDN): SPDN collects, analyses and brokers Scottish electronics based product development expertise in support of the commercialisation process. Information is accessed throughout the world via a CD-ROM database and its own website on the Internet. The commercialisation of IP is a critical area in the struggle for competitive advantage and Scottish Enterprise takes this area particularly seriously.

\subsection{The Importance of IP in a Knowledge Based Society}

The Electronics industry at $\$ 1.1 \mathrm{Tr}$ with $\$ 150 \mathrm{Bn}$ in semiconductors is not only a driver of the world economy but also a fundamental driver of national economies, witness Japan, Taiwan, Singapore and Korea. Technology is also being overtaken as the key driver, with manufacturing maturing; the Value is in IP creation. $\$ 240 \mathrm{Bn}$ has been invested by the semiconductor industry to produce products which as yet do not even exist. Consequently, New Leaders and economies will emerge who are Knowledge based and adopt the "Open Systems" model of IP utilisation.

In the Knowledge economy, the challenges of IP creation and utilisation in support of competitiveness and wealth generation afford Nations significant opportunities. The problems which currently surround intellectual capital, the difficulties in trading and protecting IP offer a market opportunity for those Nations who can simplify the process of trade and at the same time protect the owners investment.

Scottish Enterprise believes that companies are at a critical decision point on system design, driven by three main factors outside of their control.

- Semiconductor technology is progressing to the point where, within the next two years, at 0.18 micron, up to 100 million transistors can be designed onto a single chip.

- Consumer needs Consumer markets tend to have product life cycles that are very short, thus time to market is critical.

- Contract Law It can take up to twelve months to finalise a contract for usage of a single block of IP between two companies. When the target market is projected to have a product life cycle of only nine to twelve months, this length of time for contracting is uncompetitive.

A knowledge based economy will incorporate the relevant aspects of successful IP generation and the creation of a critical mass in product design and development of this nature underpins Scottish Enterprise's strategy for Cluster development which includes strategic programmes in support of Information Highways, Semiconductors, Multimedia, Software, Electronics Skills, Business birth rate and Commercialisation. 


\subsection{Developing Products in Scotland}

From the adoption of a Cluster approach we can therefore understand the requirements to be successful in a High Technology/Knowledge based economy. These can be identified as being close to a critical mass/market, maintaining competitive costs throughout the value chain, the provision of a local supply of high value services, a pool of educated and talented expertise, a strong University Base with close links to Industry and Government in pursuit of shared goals and objectives, and continuous cycle time competitiveness through the integration of the value chain from $R \& D$ to Manufacturing and distribution.

\subsection{Implications}

The implications for a government agency include:

- Support for R\&D, D\&D through the creation of value networks which identify opportunities for all stakeholders in the areas of product design and corporate research.

- Support the emergence of a Stakeholder economy where Industry, Government and Academia can share information to mutual advantage in the Knowledge Economy.

- Provide focus in a complex and demanding environment and do it now with considerable urgency.

\subsection{Challenges}

Developing a common agenda and shared vision will be no easy task in a world where everyone is busy and bottom lines and shareholder value drive essentially short term behaviour. Perhaps once we see more evidence of intellectual capital appearing on Corporate Accounts and Shareholders increasingly valuing Knowledge based organisations we will feel part of sophisticated and differentiated economies.

Developing a Common conceptual framework whereby we can freely exchange ideas and knowledge generating a "hot bed" of innovation and product development.

Consensus around priorities and allocation of scarce resources will always be difficult. It seems to me the more I work with "experts", the more difficult consensus becomes, everyone has an opinion and their personal view is clearly and obviously the right one!

Knowledge Building and developing a Learning Culture will possibly prove to be the most challenging of all. The assimilation of overwhelming volumes of data in support of a single product is difficult enough, when this is applied to multiple sectors in support of multiple clusters in pursuit of economic competitive advantage it will challenge the most sophisticated intelligent system, let alone a simple human. 


\section{CONCLUSIONS}

For a country of five million inhabitants, Scotland has made a remarkable contribution to scientific and technological advance. Our distinctive culture and traditions have fostered curiosity and the challenging of accepted beliefs. Scientists in Scotland today continue to ask why and how, and in the process contribute to the fundamental knowledge and understanding which will lie behind the advances of the 21 st century. Whether working at the leading edge of software design, in the application of advances in biotechnology, electronics or materials, our technologists continue in the tradition of the 18th century Shetland weaver whose mechanical inventions earned him the nickname Johnnie Notions.

As a country we can no longer rely simply on chance and native wit in order to secure our economic survival, much less prosperity, at a time when competition is intense the pace of change ever faster and the generation of new knowledge ever more important. We must continue to increase and build on the intellectual capital of our scientific research community, and ensure the economic potential of its work is realised by its companies. Scotland, in common with many other countries, is addressing the challenge of broadening and deepening its knowledge base, managing it more effectively and exploiting it to useful ends.

The curiosity of a poor Shetland Weaver and his ability to develop machines in pursuit of saving labour is as relevant today as it was during the Industrial revolution. Today's challenges however can be addressed through the utilisation of Supercomputers, advanced technologies and materials that the Weaver could never have imagined and perhaps this is where we should turn our attention, to the unimaginable, we are bound only by the limits of our imaginations and I can well imagine a future industry driven not by the technologists but by the behavioural psychologists, the philosophers and by people with high values.

\section{BIOGRAPHY}

\section{Jim Porter}

Jim Porter is the Head of the Information Industries Group (IIG) within Scottish Enterprise. Launched in late 1994, IIG addresses the convergence of key Industries as they create opportunities for Scotland in the Knowledge Economy. Jim has responsibility for the development of Software, Multimedia, Electronics, Optoelectronics and Semiconductor Clusters along with Electronic Commerce and Information Society Business activity. Prior to joining Scottish Enterprise, Jim had extensive experience in the manufacturing sector, working for both multinational OEMs and suppliers. Jim is a Fellow of the Royal Society of Arts and Board Member of the Scottish Electronics Forum and the Scottish Software Federation. 